\title{
Approaches to Effective Connection Between Linguistics Theory and the Chinese Teaching
}

\author{
Xiao Jiugen, Huang Shan \\ Jiangxi Normal University, College of Liberal Arts, Nanchang, Jiangxi, China
}

Email address:

jxsdxjg666666@sina.com (Xiao Jiugen),272296984@qq.com (Huang Shan)

\section{To cite this article:}

Xiao Jiugen, Huang Shan. Approaches to Effective Connection Between Linguistics Theory and the Chinese Teaching. Science Innovation. Vol. 4, No. 2, 2016, pp. 45-49. doi: 10.11648/j.si.20160402.14

Received: February 23, 2016; Accepted: March 28, 2016; Published: April 8, 2016

\begin{abstract}
The relationship between linguistics theory and the practice of basic Chinese teaching is very close. Linguistic theory provides theoretical guidance for the practice of basic Chinese teaching, and the practice of basic language teaching provides the source of language materials for the enrichment and development of linguistic theory. However, there have been serious problems on the incomplete connection between linguistics theory and the basic Chinese teaching in the teaching practice for a long time. Recently, our team has done a survey on the basic Chinese teaching, and has made an analysis on the approaches to effective connection between linguistics theory and the basic Chinese teaching. The purpose is to make Chinese teaching adhere to the basic principle "originate from language and then return to the language", and to guarantee the scientific development of basic Chinese teaching along with the right direction.
\end{abstract}

Keywords: Linguistic Theory, Chinese Teaching, Effective Connection, Way and Method

\section{语言学理论与语文教学实现有效对接的途径和方法}

肖九根, 黄珊

江西师范大学文学院, 南昌, 江西, 中国

\section{邮箱}

jxsdxjg666666@sina.com（肖九根）, 272296984@qq. com（黄珊）

\begin{abstract}
摘要: 语言学理论与基础语文教学实践的关系是十分密切的。语言学理论为基础语文教学实践提供理论指导, 而基础 语文教学实践又为语言学理论的丰富与发展提供语料来源。然而长期以来, 在实际的语文教学实践中二者存在着严重 脱节的问题。最近，我们就这一问题对基础语文教学进行了实地调查，并就其存在的实际脱节问题从途径和方法方面 如何实现二者有效对接作了一定的探讨，其目的在于促使语文教学坚持 “从语言出发再回到语言” 的基本原则，以保 证基础语文教学沿着科学化的正确方向发展。
\end{abstract}

关键词: 语言学理论, 语文教学, 有效对接, 途径与方法

\section{1. 引言}

2011年《义务教育语文课程标准》“前言”中明确指 出: “语文课程是一门学习语言文字运用的综合性、实践
性课程。义务教育阶段的语文课程, 应使学生初步学会运 用祖国语言文字进行交流沟通, 吸收古今中外优秀文化, 提高思想文化修养, 促进自身精神成长。工具性与人文性 的统一，是语文课程的基本特点。” [1] 
语言文字是人类最重要的交际工具和信息载体, 也是 人类文化的重要组成部分, 所以我们的语文课程更应致力 于培养学生的语言文字运用能力。随着时代的发展, 人们 对语言文字运用能力提出了更高的要求, 同时也将我们的 语文教学推向了一个新的改革转型时期。2001年开始新一 轮课程改革, 提倡 “自主、合作、探究” 学习, 语文教学 发生了革命性的变化。不过, 在改革的同时, 其 “重视人 文性, 忽视工具性” 的问题也越来越尖锐。具体表现在, 语文教学过度重视文学情感与价值观方面的讲授, 忽视语 言文字方面基础知识的训练。下面是某重点中学高一语文 《荷塘月色》的课堂实例, 课堂分 “诵读一赏析一讨论一 总结”四个环节进行。教师在课堂中运用了包括配乐朗诵、 多媒体演示以及小组讨论等教学方法, 师生互动良好, 整 个课堂氛围轻松热烈。语文教师设定的教学目标有三个:

(1) 知识与技能目标: 了解作者, 品味本文优美的 语言和意境及作者的散文风格。

(2) 过程与方法目标: 学习散文独特的语言技巧, 通过学习培养学生鉴赏散文的能力。

（3）情感态度与价值观目标：领悟作者蕴藏在作品 中的感情, 学习作者的爱国品质。

从教学目标来看, 这堂语文课没有什么问题。但在实 际课堂教学中, 朗读和多媒体演示之后, 本应重点赏析四、 五、六段课文, 教师仅对文章修辞艺术的运用作了一个大 略的讲解, 接着就是小组讨论 “文章体现了作者怎样的情 感”，从作者的生平一直谈到教师自身的故事。从以上实 际案例可以发现, 语文教师把重点放在思想情感与价值观 目标上。如果是一堂文学欣赏课这样做无可厚非, 但这是 一堂语文课, 更多地应把重点放在训练基础知识和基本技 能上, 只有落实了基础知识, 掌握了基本技能, 学生才能 深刻地体味作者的人生情感与价值观。有的语文教育者说: “语文课不但要让学生理解课文表达了什么, 还要让学生 理解课文语言是怎样表达的, 为什么用这个词语, 不用那 个词语; 为什么用这个句式, 不用那个句式; 为什么选这 些材料, 不选那些材料……如果丢掉了这些, 那就不是真 正意义上的语文课。”[2]这是颇有见地的。

语言学理论与基础语文教学实践的密切关系冊庸置 疑。近些年来, 针对当下基础语文教学与语言学理论严重 脱节以及语文教学中存在的其它问题, 无论语言学界还是 基础教育领域都作了一定的讨论。例如, 有的学者认为, 长期以来, 由于语文教学缺少语境理论指导, 教学仅是就 语言教语言, 因而严重制约了语文能力的提高, 主张未来 的语文教学要把语境教学作为一个发展方向。[3]而更多 的学者如王元华 [4]、刘仁增 [5]、谢建红 [6]、荣维东 [7] 等则倾向从宏观上阐述语用理论与语文教学的关系及其 在语文教学中所起的作用, 力倡在语文教学中不仅应以语 用理论来重建语文教学范式, 而且还应结合语文教学来构 建语用学理论, 从而实现“语用型”语文课程体系的建立。 毫无疑问, 学者们所作的理论探讨和实践努力, 对于促进 语文教学改革与转型是有积极意义的。不过, 语文教学是 一个十分复杂的系统工程, 究竟如何使之与语言学理论 （而不仅仅局限于语用理论）实现有效结合或对接, 还有 待学者们去作进一步的深入研究。正是基于这一点, 本文
笔者根据实地调查, 从目前二者存在严重脱节的实际情况 出发, 试图在途径与方法方面就如何实现语言学理论与基 础语文教学之间进行有效对接这一问题作些探讨, 冀望在 促使语文教学朝着科学化、高效化、实用化的正确方向发 展方面提出一些建设性意见。

\section{2. 语言学理论与基础语文教学实现有效对接的 途径}

\section{1. 高师院校在原有基础上适当增加语言学理论课的比 重}

众所周知, 现有教育领域的师资绝大部分来源于高师 院校, 高师院校所开设的课程也是为基础教学服务的。而 语言学理论不仅与语文教学有密切关系, 还对基础语文教 学实践起着重要的指导作用。那么, 在高师院校的课程中, 专业的语言学课程所占比例是多少呢? 在对江西师范大 学、江西科技师范大学、赣南师范大学、广西师范大学、 海南师范大学、上饶师范学院、乐山师范学院、安阳师范 学院、江西宜春学院、河南科技学院等十所院校师范类语 文教育专业课程设置调查之后, 我们认为有些基础课程设 置时数过少, 显然这不利于师范专业学生实际能力的培养。 下面是十所院校师范类语文教育专业课程开设的调查数 据, 如表1:

表1 十所院校师范类语文教育专业课程设置调查数据。

\begin{tabular}{llllll}
\hline 普通话 & 现代汉语 & 古代汉语 & 语言学概论 & 语音学 & 训诂学 \\
\hline 10 & 10 & 10 & 7 & 1 & 4 \\
\hline
\end{tabular}

上表可见, 大部分高师院校语文教育专业开设了普通 话、现代汉语、古代汉语、语言学概论等语言基础课程, 只有少数院校开设了语音学和训诂学这类课程。

叶蜚声、徐通铭先生指出: “语言教学需要建立在对 语言的理性认识之上, 是语言研究成果最直接的应用。” [8]而在实际的语文教学中, 我们教师缺少对语言的理性 认识是造成基础语文教学与语言学理论严重脱节的一大 原因。比如, 在我们的问卷调查中, 18-22项设制了语义 指向、语言图式、语用预设等语言学中的基本内容, 不少 教师就对这些内容疑惑不解或一知半解。由此可见, 教师 的不解或半解必然会导致他们的教学有意或无意忽略这 些方面的知识。如问卷调查 19 项是:

进行词汇教学时, 您是否有意识地运用语言学的语义 指向理论 ( )

（1）经常 (2) 有时 (3) 偶尔 (4) 从未

调查结果显示: 十五位教师中十一位选择 “从未”, 一位选择 “有时”, 两位选择 “偶尔”。多位教师认为语 义指向理论太难, 在语文教学中没有意义。之前, 我们把 基础语文教学与语言学理论脱节的主要责任归处于语文 教师，但其实问题的主因还在于高师院校的课程设置。因 此, 增加语言学理论课的比重, 加强基础语文教师语言学 知识的储备, 不仅是重要的, 也是必要的。 


\section{2. 针对高师专业编写语言学教材, 在教材方面体现师范 性的特色}

在整个基础语文教学线上, 语言学专业的毕业生不占 多数。从表 1 也显示出, 高师语文教育的课程设置多以综 合性理论课为主, 缺乏专一的语言学专业课。而理论课又 是极具概括性的, 不能完全解决基础语文教学中的实际问 题。

现代汉语是汉语言文学及相关专业必修的基础课, 其 教材主要介绍汉语的基本理论和基础知识; 语言学教材也 是综合性的阐述一般语言所具有的基本理论和基础知识。 从所编教材看, 我们发现几乎没有一部具有实用性的指导 教材来教授师范类学生如何把这些基本理论与基础知识 应用于语文教学实践中去。也就是说, 语文教学一线的教 师在很多情况下不知如何将已掌握的语言学理论及规律 来解决语文教学中的实际问题。因此, 针对高师院校培养 基础教育师资力量的具体情况来编写一部富于一定实用 性的语言学教材很有必要。

以语法而论, 枯燥难懂, 这是语文教学中教师和学 生都避之不及的难点。针对这一情况, 高师语言学教材 可以适当地引进语文课本中的一些例句来进行分析。这 样一来, 师范类毕业生下到基础教学一线时就自然而然 地知道如何把语言学理论贯彻到语文教学中去了。当然, 现有教材中一些简洁有效的方法和图表也可利用。例如, 汉语教材中名词、动词、形容词比较, 用图表作出辨别, 一目了然。这类方法的运用, 对学生学习和掌握语言知 识是很有效果的。

\section{3. 加强语文教师在教学实践中自觉运用语言学理论的 意识}

近十多年来, 教师队伍专业化是教育领域的一项重要 改革。教师资格认证和招聘都必须遵循 “专业对口” 的原 则。下表是我们对江西省多所中学 20 位语文教师问卷调查 的数据, 如表 2 :

表2 20 位中学语文教师专业对口问题调查数据。

\begin{tabular}{llll}
\hline 师范院校毕业 & 师范专业毕业 & 中文相关专业 & 跨专业 \\
\hline 12 & 16 & 18 & 2 \\
\hline
\end{tabular}

调查发现，20位语文教师中，12位来自师范院校，16 位为师范专业毕业的。其中，18位是中文相关专业的，仅2 位是跨专业的, 这就说明我们的语文教师已经具有一定的 语言学理论素养了。那么, 那些语文教师是否会自觉地将 语言学理论知识运用到实际的语文教学中去呢? 请看表 3 :

表3 某重点中学高一学生运用语言基础知识情况调查数据。

\begin{tabular}{ll}
\hline 正确使用 “的、地、得” & 正确划分 “主、谓、宾” \\
\hline $11 \%$ & $8 \%$ \\
\hline
\end{tabular}

这是来自某省重点中学高一学生的问卷结果, 从表中 可以看到学生的语言基础知识非常的贫乏。很多教师表示 语法难教, 而学生则认为语法难学, 所以在语文教学中对 语言相关知识采取 “回避” 的态度。语文课程标准在 “学 段目标与内容” 中对语音、文字、词汇、语法、修辞等语
言基础知识提出了明确要求, 在教学中应根据语文应用的 实际需要, 从所遇到的具体实例出发进行指导和点拨。要 避免脱离实际应用, 围绕相关知识的概念、定义进行 “系 统、完整” 的讲授。为什么会出现教师难教、学生难学这 一现象呢? 我们认为, 从根本上说是语文教师缺少自觉地 把语言学理论知识应用于语文教学实际的意识, 对相关知 识点有意或无意地回避, 或脱离课本去讲。比如讲修辞, 教师通常采取的教学步骤是, 先对比喻、借代、夸张等下 定义, 然后举例, 最后学生仿句。但是我们认为, 许多相 关的语言理论知识只有联系文本讲解, 才能取得好的效果。 同样以《荷塘月色》为例, 在讲到 “叶子出水很高, 像亭 亭的舞女的裙” 时, 教师可以指出作者运用了比喻手法来 写荷叶的风姿, 由“出水很高”联想到“亭亭的舞女的裙”,

两者不仅神似, 而且还写出了荷叶的动态美。另外, 在这 篇课文中, 学生第一次接触 “通感” 这一修辞手法, 教师 将 “通感” 的定义联系 “微风过处, 送来缕缕清香, 仿佛 远处高楼上渺茫的歌声似的” 这一句, 引导学生理解由嗅 觉向听觉转移: “缕缕清香” 与 “沙茫的歌声” 在许多方 面有相似之处, 这样学生很快就能学会, 并能更好地领悟 课文。可见语言学理论知识在语文教学中有多么的重要, 因此加强语文教师运用语言学理论知识的自觉意识是十 分必要的。

\section{3. 语言学理论与基础语文教学实现有效对接的 方法}

\section{1. 语言研究者要多参与语文教学实践, 多培养研究型 语文教师, 加强语言研究和语文教学之间的交流与 沟通}

有人说, 语文教师必须具有教学科研意识, 要从实践 型、经验型向理论型、研究型教师转变。[9]而目前的实 际状况怎样呢? 其状况是: 语文教师大多固然不是研究型 的, 就是语言研究者其基础语文教学经验也很少, 甚至基 本上没有, 这就无法把语言学理论与语文教学实践有机地 结合在一起。这正如有的学者所指出的那样: 广大语文教 育工作者对现代语言学比较陌生, 而现代语言学研究者对 语文教育也比较陌生。[10]这种陌生的关系是语言学理论 与基础语文教学脱节的另一重要原因。可以这么说, 要实 现两者之间的有效对接, 改变基础语文教学的现状, 使语 文教学从现代语言学中汲取营养, 就必须使双方有所沟通。 双方要进行有效沟通, 语文教育者就应加强现代语言学理 论的学习, 提高语言学理论素养和理性认识。而要解决这 一根本性的问题, 一方面要加强高校基础学科建设: 师范 院校要相应地增加语言学理论课程, 并针对专业师范类学 生编写为基础教育服务的语言学实用教材等, 这在上文已 经提出过; 另一方面语文教师也应不断地提升自我: 加强 语言学理论学习, 提高语言学理论水平。语文教师如果“没 有深厚的语言学修养, 教学不可能丰富, 更不可能有趣”。 [11] 只有加强自身的语言学理论修养, 语文教师才能有意 识地自觉应用语言学理论来解决教学中的实际问题, 并且 使自己不仅成为一个教育者, 还是一个研究者。另外, 我 们的语言研究者看似与语文教学没有太大的关系, 但其实 
二者关系十分密切。王宁先生认为: “语文的基础是语言, 它是通过语言认知、语言传意和语言训练来提高人的思维、 认识与表达的能力和素养的。” [12]正因为这样, 语言研 究者与语文教师有着共同关心的语言话题。语言研究者研 究的多是生活中使用的语言现象, 如区分语气词 “的” 和 结构助词 “的” :

（1）他是三班的（学生）。（结构助词）

(2) 班主任今天会回来的。（语气词）

(3) 这本书是新发的。（语气词）

（4）这本是新发的（书）。（结构助词）

这既是生活中经常听到的, 也是语言研究和语文教学 所关注的。也就是说, 语言研究者要把研究成果运用到语 文教学实践中去, 仅仅单靠研究文本是远远不够的, 还需 到语文教学一线中去发现问题。所以, 语言学专家应去中 小学开展专业讲座, 听取语文教学一线教师的意见, 与基 础语文教学的教师直接展开对话。

\section{2. 语文教师课堂教学不仅教授语言理论知识, 更多的 应理论联系实际，授之以方法}

无论语文教学过程还是语文学习过程, 语言理论知 识一直是基础语文教学中的一个难点, 教师对之深感力 不从心, 学生则疑惑不解。在我们的调查中, 有约百分 之七十的学生认为语言知识很重要, 百分之九十四的学 生觉得语言知识很难。例如, 调查中我们设制了一个句 子成分的划分:

（1）小明在班上是跑步最快的学生。

（2）小霞看书看得废寝忘食。

结果是 150 个学生中没有一个正确划对主谓宾的, 错 误率竟达 $100 \%$ 。这种情况在语文考试中也有所体现，通过 对省内某重点高一年级第三次月考语文试卷基础知识错 误率的统计, 发现语病题的错误率高达 $64 \%$ 。在口头访谈 时, 大部分学生基本能说出主谓宾的概念, 而实际运用却 不容乐观, 所以我们认为教师在教授语言理论知识时不仅 要教授理论, 更应教授方法, 让学生能运用所学去解决实 际问题。

检阅语文考试卷, 学生错误率最高的也是语病题。如 下面一道考题:

下列句子中，没有语病的一项是（）

（1）由于河北运输烟花爆竹的车辆发生爆炸，致使 连霍高速公路河南渑池段义昌大桥南半幅桥面垮塌, 造成 10 人死亡, 11 人受伤。

（2）理科综合、文科综合的考试形式，对许多习惯 了单科考试的高三学生, 最初的确会感到不适应。

（3）中新记者看到，“桑迪”（县风）带来的罕见 狂风呼啸而过, 凄厉的鸣叫令人心惊, 大暴雨随着风势倾 泻下来, 漫天皆雨水。

（4）近日，有关延迟退休的多种备选方案已提交有 关部门讨论, 可是有一个非常现实却容易被忽视的问题, 延退之后, 有幼儿的家庭怎么办?

通过分析，我们知道选项（1）缺主语。选项（2）不 合逻辑, 主客体颠倒, 应为 “许多习惯了单科考试的高三 学生, 对理科综合、文科综合的考试形式, 最初的确会感
到不适应”。选项 (3) 谓宾搭配不当, “看到” 不能用 “鸣 叫” 搭配。所以，选项（4）是正确的。这一题中涉及到的 句法错误都属于黄伯荣、廖序东《现代汉语》教材里的第 五章第七节 “常见的句法失误” 中的知识一一搭配不当、 残缺和多余、语序不当、句式杂糅。[13] 所以, 教师课堂 教学或试卷讲评应结合考试中出现的问题, 教给学生解决 问题的方法。比如, 句法问题, 不仅要掌握主谓宾的概念 意义和句子结构规律, 还应从反面分析为何不这样组织句 子, 通过训练以提高学生发现问题、解决问题的能力。

\section{3. 将语义学、语用学理论与方法引入语文课堂, 加强语 境教学}

关于语言理论知识, 很多教师和学生的回答是“语法” 和 “词汇” ，几乎无人提及 “语义”、“语用” , 这也是 语言教学中的一个缺失。北大出版的修订版《语言学纲要》, 全书九章概述了语言学理论的各个方面。在整个理论板块 中, 我们发现有关语义、语用的内容只占第五章的一个很 少部分, 而语义、语用理论在语文教学中却又有着非常重 要的作用。对于这一点, 有的学者是这样认为的: “意义 是语文教学永恒不变的旋律和核心, 在母语的语文教学里, 最有用的语言学知识是语义而不是语法。”[14]比如说语 境, 我们的语言是在一定的交际环境中使用的, 在分析语 言现象时就必须把它和它所依赖的语言环境联系起来, 而 不能把一个语言片段孤立起来分析。另外, “语用”之重 要在语文考试中也有所体现。如高考语文试卷第二大题小 阅读, 最常见的考题为: “对文意理解不准确的一项是 ( )”。 这一类题型往往看似容易, 实际上学生失分率是很高的, 它需要学生联系上下文语境分析才能得出正确答案。

语用学理论对学习语言其它方面的知识也是非常有 用的, 其中词汇教学表现得最为突出。如 “一词多义” 现 象, 正是这种复杂性导致学生很多时候不能正确运用词语, 而 “一词多义” 又是针对不同语境中的实际语用现象而言 的。所以, 词语教学如能运用语用学中的语境理论进行, 所遇问题就迎刃而解了。

\section{4. 结束语}

总而言之, 语言学理论与基础语文教学脱节是我们当 今面临的一个实质性问题, 语文教学改革多年并未取得明 显成效, 归根到底与二者之间在一定的程度上没有实现有 效对接是有极大关系的。本文在实际调查的基础上，提出 实现二者进行有效对接的基本途径和可行方法, 旨在促使 不论是语文教者还是语文学者 “都必须坚持 “从语言出发 再回到语言” 的基本教学原则, 这是落实学科理论的关键, 也是促进语文教学科学发展的保证”。[15]如果实现了这 一点, 不仅现状有所改观, 而且还会出现语言研究与语文 教学良性互动的一个崭新的双赢局面。

\section{致谢}

本文为中国江西省高等学校教学改革科研课题《高师 语言学理论与基础语文教学实践问题研究——关于如何 
加强高师语言学理论与基础语文教学实践对接问题的思 考》（批准号JXJG-13-2-4）的阶段性成果之一。

\section{参考文献}

[1] 中华人民共和国教育部. 义务教育语文课程标准 [M]. 北京: 人民教育出版社, 2011：1。

[2] 乐鸣. 对当前语文课堂教学从现象到理论的辩证思考 $[\mathrm{J}]$. 语文教学研究 2007, vol.2(11)：6。

[3] 孔凡成. 语境教学: 语文教学的发展方向 [J]. 语文建设 2014 (2) : 22-24。

[4] 王元华. 语用学与基础教育语文课程改革 $[\mathrm{J}]$. 课程 - 教 材・教法2014, vol. 34 (9) : 25-30。

[5] 刘仁增. 语用: 语文教学的价值重塑与范式重构 $[\mathrm{J}]$. 课 程・教材・教法2014, vol. 34 (6) : 55-60。

[6] 谢建红. 语用学的语言观对语文教学理念的启示 [J]. 语文 建设2015（11）：19-20。
[7] 荣维东杜娟. 语文教育亟待语用转型与体系重建 [J]. 中国 教育学刊2015（5）：44-49。

[8] 叶蜚声徐通铭. 语言学纲要 $[\mathrm{M}]$. 北京: 北京大学出版社, 2010: 5-6。

[9] 李竹平. 提升语文教师专业素养至关重要——读新《课程语 文教学论有》感 $[J]$. 人民教育2011(17)：62。

[10] 郑振峰宋文辉李冬鸽. 现代语言学和中学语文教学 [J]. 河 北师范大学学报2009, vol. 11 (9)：106。

[11] 王宁. 语言学在语文教学中的作用 $[J]$. 语文建设2002 (3) : 17 。

[12] 王宁. 汉语语言学与语文教学 [J]. 中国社会科学2000(3): 170。

[13] 黄伯荣廖序东. 现代汉语 [M]. 北京: 高等教育出版社, 2011: 113-120。

[14] 王元华. 语用视野下的语文教学 [M]. 北京: 北京师范大学出 版社, 2012: 14。

[15] 张传宗. 构建以语言教学为核心的语文教学体系 [J]. 课 程・教材・教法2011, vol. 31(3)：38。 